\title{
PENDAMPINGAN KAMPUNG PENDIDIKAN -KAMPUNGE AREK SUROBOYO (KP KAS) BANYU URIP KATEGORI MADYA
}

\author{
Tegowati \\ Sekolah Tinggi Ilmu Ekonomi Indonesia (STIESIA) Surabaya \\ Email:tegowati@stiesia.ac.id
}

\begin{abstract}
Abstrak
Sebagai perwujudan salah satu tridharma perguruan tinggi, khususnya Pengabdian kepada Masyarakat, STIESIA Surabaya memberikan pendampingan penyusunan Portofolio Lomba Kampung Pendidikan Kampunge Arek Suroboyo (KP-KAS) bagi Kelurahan Banyu Urip, Kecamatan Sawahan, Kota Surabaya. Kampung (Kelurahan) yang mengikuti Lomba KP-KAS diwakili oleh Rukun Warga $(R W)$ atau beberapa $R W$ dengan melibatkan beberapa Rukun Tetangga (RT). Dalam Lomba KP-KAS wajib menyusun Portofolio yang telah ditetapkan oleh Pemerintah Kota Surabaya. Dalam penyusunan Portofolio Lomba KP-KAS, beberapa Kelurahan memandang perlu adanya pendampingan dari unsur masyarakat yang kompeten, misalnya dari Lembaga Swadaya Masyarakat (LSM) atau akademisi dari Perguruan Tinggi. Kelurahan Banyu Urip, Kecamatan Sawahan, Kota Surabaya, adalah salah satu Kelurahan yang merasa perlu adanya pendampingan dalam penyusunan Portofolio Lomba KP-KAS tahun 2018. Hasil yang dicapai dari pendampingan ini adalah: a). Tim RT, RW, dan Kelurahan Banyu Urip Kecamatan Sawahan mampu menghasilkan Portofolio Lomba KP-KAS yang tersusun sesuai dengan ketentuan Pemerintah Kota Surabaya. b) Tim RT, RW, dan Kelurahan Banyu Urip Kecamatan Sawahan mampu mengeksplorasi potensi dan keunggulan-keunggulan yang dimiliki, serta mengungkapkannya dalam Portofolio Lomba KP-KAS secara optimal. c) Tim RT, RW, dan Kelurahan Banyu Urip Kecamatan Sawahan mampu menyelesaikan penyusunan Portofolio Lomba KP-KAS tepat waktu.
\end{abstract}

Kata Kunci: KP KAS, Portofolio, Kampung Kreatif, Kampung Layak Anak

\begin{abstract}
As an embodiment of one of the tridharma of higher education, especially Community Service, STIESIA Surabaya provided assistance in compiling the Portfolio of Kampunge Arek Suroboyo (KP-KAS) Educational Village Contest for Banyu Urip Village, Sawahan District, Surabaya City. Villages (Kelurahan) participating in the KP-KAS Contest are represented by RWs or RWs with several RTs. In the KP-KAS Competition, it is compulsory to compile a Portfolio set by the Surabaya City Government. In the preparation of the KP-KAS Portfolio Contest, several Kelurahan saw the need for assistance from competent elements of the community, for example from Non-Governmental Organizations (NGOs) or academics from Universities. Banyu Urip Village, Sawahan Subdistrict, Surabaya City, is one of the Kelurahan who feels the need for assistance in the compilation of 2018 KP-KAS Competition Portfolio. The results achieved from this assistance are : a). KP-KAS Competition Portfolio arranged in accordance with the provisions of the Surabaya City Government. b) The RT, RW, and Kelurahan Banyu Urip Sawahan subdistrict are able to explore the potential and advantages they have, and to disclose it in the KPKAS Competition Portfolio optimally. c) The RT, RW, and Kelurahan Banyu Urip Sawahan subdistricts were able to complete the preparation of the KP-KAS Competition Portfolio on time.
\end{abstract}

Keywords: KP KAS, Portfolio, Creative Village, Village Worthy of a Child 


\section{PENDAHULUAN}

Pendampingan STIESIA tahun 2018 difokuskan pada Kampung kategori Madya. Kampung kategori Madya memiliki 7 karakteristik: (1) Kampung Kreatif; (2) Kampung Belajar; (3) Kampung Asuh; (4) Kampung Aman; (5) Kampung Sehat; (6) Kampung Literasi dan (7) Pemuda Penggerak Literasi. Pemerintah Kota Surabaya meyakini bahwa untuk menjadikan Surabaya sebagai Kota Pendidikan yang memiliki tujuh karakteristik tersebut, harus dimulai dari lingkungan (entitas) yang lebih kecil, yaitu Kelurahan (dalam hal ini disebut sebagai Kampung). Oleh karena itu, Pemerintah Kota Surabaya berupaya menumbuhkan kesadaran masyarakat Kampung untuk menjadikan kampung mereka sebagai Kampung Pendidikan. Salah satu program yang dilaksanakan oleh Pemerintah Kota Surabaya untuk menumbuhkan kesadaran tersebut adalah menyelenggarakan Lomba "Kampung Pendidikan - Kampunge Arek Suroboyo" (KP-KAS). Program ini merupakan lanjutan dari program pemerintah kota pada tahun 2016 yang disebut "Inisiasi Kampunge Arek Suroboyo" (IKAS).

Kampung (Kelurahan) yang mengikuti Lomba KP-KAS diwakili oleh Rukun Warga (RW) atau beberapa RW dengan melibatkan beberapa Rukun Tetangga (RT) yang memenuhi syarat dan siap untuk itu. RT/RW yang ditunjuk untuk mewakili Kelurahan dalam Lomba KP-KAS wajib menyusun Portofolio yang telah ditetapkan oleh Pemerintah Kota Surabaya. Dalam penyusunan Portofolio Lomba KP-KAS, beberapa Kelurahan memandang perlu adanya pendampingan dari unsur masyarakat yang kompeten, misalnya dari Lembaga Swadaya Masyarakat (LSM) atau akademisi dari Perguruan Tinggi.

Kelurahan Banyu Urip, Kecamatan Sawahan, Kota Surabaya, adalah salah satu Kelurahan yang merasa perlu adanya pendampingan dalam penyusunan Portofolio Lomba KP-KAS tahun 2018. Sebagai perwujudan salah satu tridharma perguruan tinggi, khususnya Pengabdian kepada Masyarakat (PkM), STIESIA Surabaya memberikan pendampingan penyusunan Portofolio Lomba KP-KAS bagi Kelurahan Banyu Urip, Kecamatan Sawahan, Kota Surabaya tersebut. Tujuan Pendampingan ini adalah: a).Tim RT, RW, dan Kelurahan Banyu Urip Kecamatan Sawahan mampu menghasilkan Portofolio Lomba KP-KAS yang tersusun sesuai dengan ketentuan Pemerintah Kota Surabaya. b) Tim RT, RW, dan Kelurahan Banyu Urip Kecamatan Sawahan mampu mengeksplorasi potensi dan keunggulan-keunggulan yang dimiliki, serta mengungkapkannya dalam Portofolio Lomba KP-KAS secara optimal. c) Tim RT, RW, dan Kelurahan Banyu Urip Kecamatan Sawahan mampu menyelesaikan penyusunan Portofolio Lomba KP-KAS tepat waktu.

Dalam pelaksanaannya, faktor yang mempengaruhi perwujudan kota layak anak (KLA) adalah komitmen (Hamudy, 2015). Peran orang tua, guru, tokoh agama dan tokoh masyarakat sangat penting dalam proses pendidikan dan dukungan pembelajaran pada anak (Hermino, 2016). Pemberdayaan masyarakat kampung kota dalam penataan lingkungannya memberikan dampak yang signifikan dalam waktu singkat dengan tetap berdasarkan pada aturan perencanaan kota yang telah dirumuskan sebelumnya. Penataan dilakukan dalam skala kecil namun mampu menghasilkan dampak dan kualitas yang baik bagi kota karena menghasilkan reaksi berantai, dimana penataan satu spot akan memberikan pengaruh pada spot lain dan akhirnya akan berdampak luas bagi kota (Hanafiah \& Doddy, 2017).

Keberhasilan implementasi Program KP KAS di kampung kota sangat dipengaruhi kondisi sosial-budaya masyarakatnya dan kerjasama serta komitmen antar elemen masyarakat dengan pemerintah. Kegiatan berbasis komunitas lokal dan sistem pembinaan yang terpadu dapat menjaga keberlanjutan kampung kreatif (Saraswati dkk. 2016). Kreativitas memegang kunci 
dalam membuat perubahan, yang mendorong seseorang untuk memulai gerakan menuju suatu perubahan, dan permasalahan yang ada dapat diselesaikan melalui kreativitas (Rahmany dan Djajadiningrat,2014). Indikator Kota Layak Anak dibedakan menjadi dua ditinjau dari pendidikan dan di sekolah: 1. Implementasi KLA dalam pendidikan meliputi: peran dunia usaha, fasilitas informasi, kawasan tanpa rokok, pendidikan anak usia dini, sekolah ramah anak, wajib belajar 12 tahun, fasilitas perjalanan anak dari dan ke sekolah serta fasiltas kreasi dan rekreasi (Said et al, 2017).

Menurut Dianingrum dkk (2017) delapan kriteria yang dapat dijadikan referensi untuk mengatur periode pengembangan program peningkatan Kampung di Surabaya. Kriteria ini meliputi: Aspek Peningkatan 1. Aspek peningkatan fisik; 2. Aspek peningkatan sosial; 3. Aspek perbaikan ekonomi Pemberdayaan; 4. Penerapan pemberdayaan; 5. Tahapan pemberdayaan Peran; 6. Pengambilan keputusan Partisipasi komunitas; 7. Tingkat partisipasi 8. Formulir Partisipasi

\section{METODE PELAKSANAAN}

Metode pendampingan dilaksanakan dengan cara memberikan bimbingan teknis penyusunan Portofolio KP-KAS Banyu Urip Kecamatan Sawahan Kelompok KAMPUNG KREATIF, yang mencakup: A) Kepatuhan pada aturan dan sistematika portofolio KPKAS; B) Eksplorasi potensi dan keunggulan yang dimiliki RT/RW/Kelurahan; C) Penggunaan bahasa Indonesia yang baik dan benar; D) Penyajian data, informasi, tabel, gambar dan foto dokumentasi; E) Penyediaan bukti-bukti pendukung setiap pernyataan dan kegiatan; F) Tata tulis dan layout portofolio.

Untuk menghasilkan Portofolio KPKAS Banyu Urip Kecamatan Sawahan secara komprehensif, pendampingan penyusunan Portofolio KP-KAS kelompok KAMPUNG KREATIF dilaksanakan secara koordinatif dengan para pendamping lain pada kelompok KAMPUNG ASUH, KAMPUNG AMAN, KAMPUNG KREATIF, KAMPUNG SEHAT, KAMPUNG LITERASI,
PENGGERAK PEMUDA KAMPUNG LITERASI yang dalam hal ini didampingi oleh tim STIESIA (Rika Rahayu, S.M., M.B.A.; Anang Subardjo, S.E., M.M.; Andi Wibowo, S.E., M.B.A., Ak., CA.; Astri Fitria, S.E., M.Si., Ak., CA.)

\section{HASIL DAN PEMBAHASAN}

Dalam menyelenggarakan kampung kreatif di RW 09 Kelurahan Banyu Urip berjalan dengan baik, tokoh masyarakat dan seluruh warga RW 09 membuat sebuah perjanjian atau pakta integritas yang berisi kesepakatan-kesepakatan tentang hal-hal sebagai berikut :

\section{1). Memperbanyak Kreativitas Anak:}

- Mengajak dan mengajarkan anak untuk berkreasi dengan bahan-bahan sampah kering yang bisa didaur ulang seperti bungkus kopi dijadikan tas. Kegiatan ini dilakukan 1 bulan sekali setiap minggu pertama, dan dilakukan pada malam hari jam $18.00-21.00$ bertempat di balai RT 13, sedangkan untuk bahan baku dikumpulkan dari pemilahan sampah kering yang sudah berjalan yang didapatkan dari warga.

- Mengajak dan mengajarkan anak untuk berkreasi benang wol dijadikan sebagai syall, baju, taplak, kaos kaki dll dan dilakukan berbarengan dengan sampah daur ulang. Bahan baku diperoleh dari toko penjualan benang rajut.

- Pembuatan jamu tradisional, bahan baku diperoleh dari tanaman di wilayah RT 13.

2). Mengajak Anak Untuk Melakukan Permainan Edukatif:

- Mengajak anak-anak / balita bermain tema (transportasi) pada saat posyandu. Jadi selama posyandu berlangsung, tidak hanya dilakukan timbang BB, pemberian vitamin, tetapi juga mengajak anak untuk bermain permainan edukatif. 


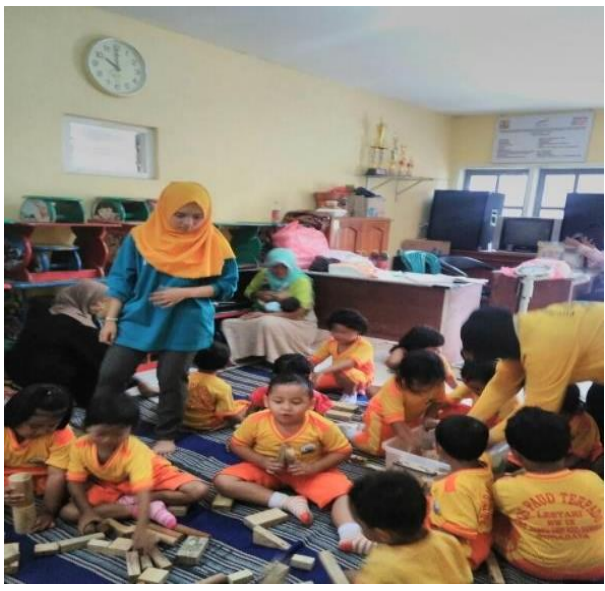

Gambar 1: mengajak anak permainan edukatif

Sumber: data RT 11 RW 09 Banyu Urip Kidul

\section{3). Pembuatan Kursi Dari Daur Ulang \\ Tong Bekas}

Pemberdayaan karang taruna dan tenaga muda dalam pelatihan dan pembuatan kursi dari tong bekas mempunyai tujuan yaitu untuk menghasilkan barang dari bahan bekas yang nantinya bisa memiliki nilai jual/nilai ekonomisnya dapat dimanfaatkan untuk kebutuhan tambahan kartar dan tenaga pembuatnya. Proses pembuatan dilakukan selama 3 hari untuk 1 kursi. Total modal usaha Rp. 565.000. Rencana kursi tersebut akan dijual seharga Rp.850.000

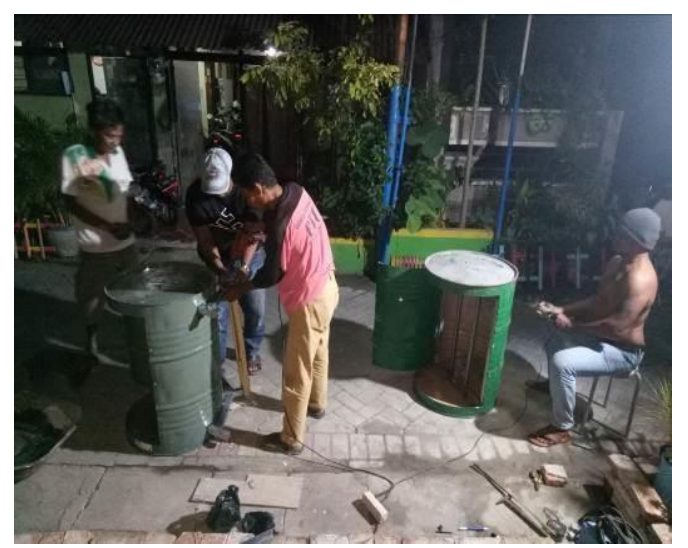

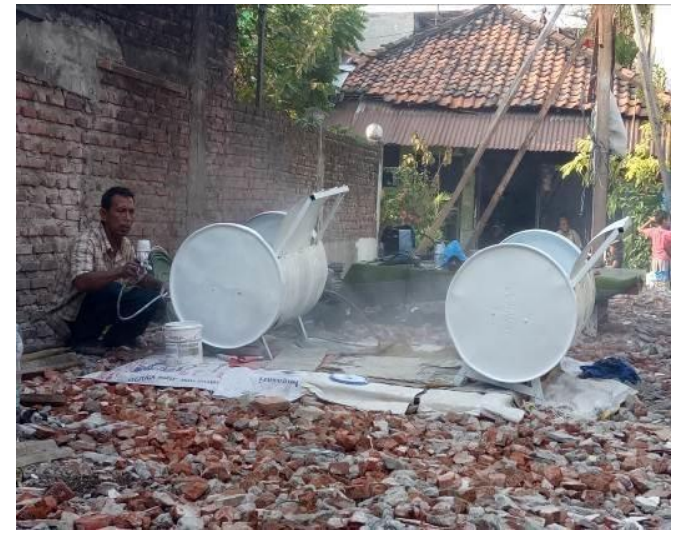
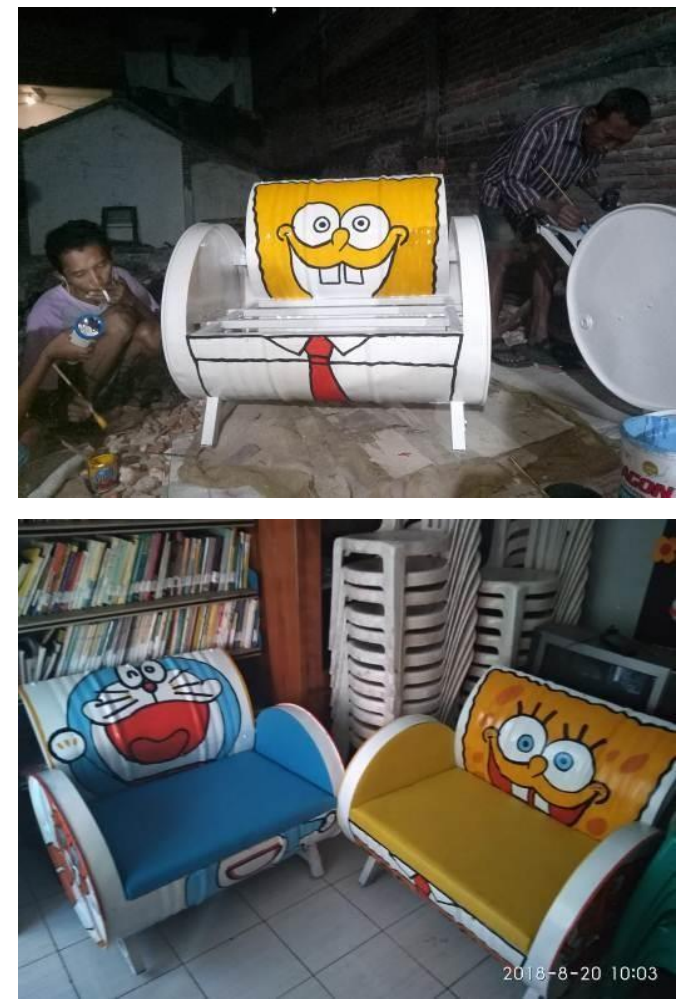

Gambar 2: proses pembuatan kursi daur ulang sampai sudah jadi

Sumber: data RT 11 RW 09 Banyu Urip Kidul

\section{4). Kursus Bengkel Pendingin}

Kursus ini diadakan setiap hari, di samping pelaksanaan teori/pembekalan teori juga praktek langsung bekerja dilapangan. Pengembangan keterampilan di bidang pendingin ruangan $(\mathrm{AC}$, lemari es, mesin cuci) hasil dari pengembangan pelatihan dan mengembangkan sendiri kreatifitas anak didik yang diberikan bapak Joko. Fungsi dari pelatihan yang di berikan bapak joko 
untuk menjaring anak-anak yang belum bekerja/tidak mempunyai pekerjaan supaya bisa membuka lapangan kerja sendiri setelah mengikuti pelatihan dari beliau.

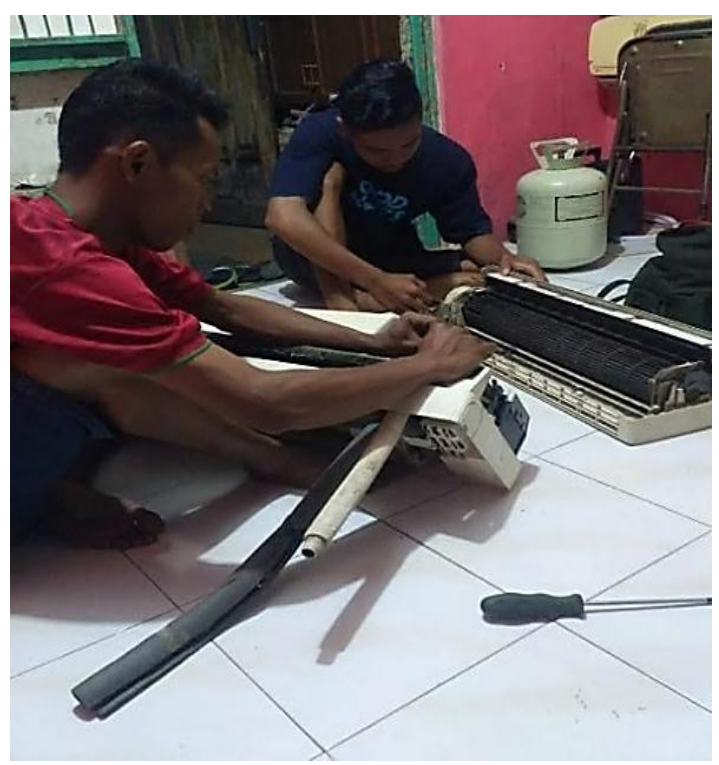

Gambar 3: kursus bengkel pendingin Sumber: data RT 11 RW 09 Banyu Urip Kidul

\section{KESIMPULAN}

KP KAS merupakan program yang diselenggarakan oleh pemerintah kota Surabaya dan Dinas Pengendalian Penduduk, Pemberdayaan Perempuan dan Perlindungan Anak (DP5A) kota Surabaya kerjasama dengan akademisi Dinas Perpustakaan dan LSM mengajak seluruh warga kampung untuk sama-sama memastikan dan menjadikan lingkungan Suroboyo sebagai lingkungan yang ramah untuk tumbuh kembang anak, melakukan proteksi pada anak dan menciptakan suasana kampung yang nyaman serta mempersiapkan generasi muda Surabaya berkembang dengan baik dan aman untuk menjadi generari mandiri dengan berbagai kreativitas yang tinggi

\section{UCAPAN TERIMA KASIH}

Dalam program pendampingan Kampung Pendidikan Kampung'e Arek Suroboyo (KP KAS) ini kami ucapkan banyak terima kasih kepada semua pihak atas kontribusi yang telah diberikan dalam pelaksanaannya:

1. Dr. Nur Fadjrih Asyik, S.E., M.Si., Ak., CA. selaku ketua STIESIA Surabaya.

2. Prof. Ir. Hening Widi Oetomo, M.M. PhD., selaku ketua LP2M STIESIA Surabaya.

3. Pemerintah kota Surabaya dan Dinas Pengendalian Penduduk, Pemberdayaan Perempuan dan Perlindungan Anak (DP5A) kota Surabaya yang telah menyelenggarakan lomba KP KAS sebagai wujud komitmen untuk terus membangun Surabaya sebagai kampung yang ramah anak dan jauh dari kemungkinan penyimpangan sosial, terutama pada generasi muda yang merupakan generasi harapan bangsa.

4. Dinas Perpustakaan, sebagai pelopor gemar membaca pada anak dan penanggung jawab atas KP KAS untuk kategori kampung literasi, pemuda penggerak literasi, dan kampung binaan (pengimbasan).

5. Kelurahan RW 09 Banyu Urip kecamatan Sawahan atas partisipasi dan kerjasamanya dalam lomba KP KAS 2018.

6. Tim PKM STIEISA (Rika Rahayu, S.M., M.B.A.; Anang Subardjo, S.E., M.M.; Andi Wibowo, S.E., M.B.A., Ak., CA.; Astri Fitria, S.E., M.Si., Ak., CA.) atas kerjasamanya dalam penyelesaian portofolio kampung pada lomba KP KAS 2018.

7. LSM dan seluruh warga Surabaya, yang telah mendukung dan ikut serta dalam mengikuti lomba KP KAS 2018 sehingga perlombaan dapat berlangsung dengan meriah dan kompetitif 


\section{REFERENSI}

Dianingrum, A., Muhammad, F., \& Dewi S. 2017. Development of Kampung Improvement Program in Surabaya, Indonesia. The International Journal of Engineering and Science (IJES) 6( 7),41-47.

Hamudy, M.,I.,A. 2015. Worth The Effort to Achieve The City of Children in Surakarta Makassar. Jurnal Bina Praja, 7(2), 149-160.

Hanafiah, U. I. M., \& Doddy,F.A. 2017. Redefinisi Ruang Publik Pada Kampung Kreatif Pasundan Studi Kasus : Koridor Tepian Sungai Cikapundung, RT 02 RW 04, Kelurahan Balonggede, Kecamatan Regol, Kota Bandung, Jawa Barat. Jurnal IDEALOG Ide dan Dialog Indonesia, 2(2), 124-137.

Hermino, A. 2016. The Effectiveness of Implementation School-Based
Management in the Central Highlands of Papua Indonesia. International Journal of Education and ResearcH, 4(10), 291-304.

Rahmany, R., and S.T. Djajadiningrat. 2014. Methodology of Generating 'Creative Tourism Kampung' and Stakeholders Engagement Analysis in Kampung Kreatif Dago Pojok Project. Journal of Business and Management, 3(5), 589611.

Saraswati T. W., S.N. Sabatini, D. Rachmaniatus, T. M. S. Kasman. 2016. Identifikasi Kampung Kreatif Sebagai Strategi Kota Tangguh . Prosiding Temu Ilmiah IPLBI, 15-20.

Said, M.R., Murtono, dan S.Utaminingsih. 2017. Implementasi Kota layak Anak di Kabupaten Demak. Jurnal Refleksi Edukatika, 8(1), 99-106. 